\title{
Knowledge and Attitude towards Cervical Cancer: A Case Study of Undergraduate Students in Imo State, Nigeria
}

\author{
Ugonma Winnie Dozie ${ }^{1 *}$, Chiamaka Lilian Nwadi' ${ }^{1}$, Chika Polycarp Umunakwe ${ }^{2}$, \\ Nneka Eleano Asuzu1, Iheoma Rosemary Obikonu1, Ikechukwu Nosike Simplicius Dozie ${ }^{1}$ \\ ${ }^{1}$ Department of Public Health, Federal University of Technology, Owerri, Nigeria \\ ${ }^{2}$ Department of Agricultural Extension, Federal University of Technology, Owerri, Nigeria \\ Email: *ugonmadozie@gmail.com
}

How to cite this paper: Dozie, U.W., Nwadi, C.L., Umunakwe, C.P., Asuzu, N.E., Obikonu, I.R. and Dozie, I.N.S. (2020) Knowledge and Attitude towards Cervical Cancer: A Case Study of Undergraduate Students in Imo State, Nigeria. Open Access Library Journal, 7: e6441.

https://doi.org/10.4236/oalib.1106441

Received: May 18, 2020

Accepted: June 20, 2020

Published: June 23, 2020

Copyright $\odot 2020$ by author(s) and Open Access Library Inc.

This work is licensed under the Creative Commons Attribution International License (CC BY 4.0).

http://creativecommons.org/licenses/by/4.0/

http://creativecommons.org/licen

\begin{abstract}
The study investigated the knowledge and attitude towards cervical cancer in Imo State, Nigeria. A sample of 230 female undergraduate students selected from Imo State University participated in the study. Data were collected using structured questionnaire and were analyzed using percentage, mean and Chi-Square. The result showed that the majority (81.7\%) of the respondents were in their sexually active ages, the majority $(70.0 \%)$ of the respondents had a low knowledge of cervical cancer and about 53\% did not know about its causes. On the attitude towards screening, $82.6 \%$ of the respondents had never done pap smear test and $80 \%$ were afraid of going for it. The result further showed a generally negative belief about cervical cancer infection. The hypothesis tested showed a significant relationship between level of knowledge and attitude towards cervical cancer screening at $p=0.000$. Therefore, increased sensitization targeting women in sexually active ages as a way of improving their knowledge on cervical cancer was recommended.
\end{abstract}

\section{Subject Areas \\ Epidemiology, Public Health}

\section{Keywords}

Cervical Cancer, Knowledge Level, Attitude, Young Women, Nigeria

\section{Introduction}

Cervical cancer is a rare long-term outcome of persistent infection of the lower 
genital tract by one of about 15 high-risk human papillomavirus (HPV) types, which is termed the "necessary" cause of cervical cancer [1] [2]. Of the estimated 530,000 new cervical cancer cases annually, HPV 16 and HPV 18 account for about $71 \%$ of cases while HPV types 31,33, 45, 52 and 58 account for another $19 \%$ of cervical cancer cases [3] [4]. Cervical cancer is the fourth most frequent cancer in women after breast, colorectal and lung cancer with an estimated 570,000 new cases and 311,000 deaths in 2018, representing 6.6\% of all female cancers [5] [1]. One in ten women is diagnosed with it and every two minutes, a woman dies of it globally [6]. Highest incidence of cervical cancer related death occurs among middle-aged women about 30 - 40 years [7]. The estimated age-standardized incidence of cervical cancer is 13:1 per 100,000 women globally and varied widely among countries, with rates ranging from less than 2 to 75 per 100,000 women in eastern, western and southern Africa. The highest incidence was estimated in Eswatini, with approximately $6.5 \%$ of women developing cervical cancer before age 75 years. Globally, the average age at diagnosis of cervical cancer was 53 years, ranging from 44 years (Vanuatu) to 68 years (Singapore). The global average age at death from cervical cancer was 59 years, ranging from 45 years (Vanuatu) to 76 years (Martinique) [5].

It is more common in low and middle-income countries where it is the most common cancer in incidence among women and the third most common in terms of mortality. Most of the new cases and deaths (approximately $85 \%$ and $90 \%$ respectively) occur in low-resource regions or among people from socioeconomically weaker sections of society [8] [1]. By 2030, cervical cancer will be responsible for the death of 443,000 women worldwide [9] (World Health Organization, WHO, 2015), 98\% of the predicted death will occur in low-income countries with sub-Saharan Africa having the highest number of deaths [10]. In Nigeria, almost 15,000 new cases of cervical cancer are diagnosed annually and age-standardized incidence rate is 27.1 per 100,000 [8].

Beddoe (2019) [11] noted that Nigeria has developed a national cancer control policy that incorporates cervical cancer awareness, implementation of HPV-DNA testing/VIA with the treatment of pre-cervical lesions and implementation of HPV vaccination programmes [8]. Yet, the incidence of the disease is growing in the country. Bisi-Onyemaechi et al. (2018) [12] found that the utilization of HPV vaccines in the treatment of the disease is low. Walker et al. (2002) [13] reported a low awareness of the disease in Africa and this cuts across different literacy levels. In Nigeria, only $4.2 \%$ of the 500 attendees of a maternal and child health clinic in Lagos were aware of cervical cancer and over $80 \%$ of 139 patients with advanced cervical cancer had never heard about the disease. Also, only $9 \%$ of the patients knew the disease was cancer-related [14].

Students have been reported to have poor knowledge of cervical cancer and screening in developing countries [15]. According to Buga (1998) [16] the overall knowledge of cervical cancer was very poor among female university students in South Africa. Anorlu et al. (2008) [17] noted that sexual intercourse before 18 
years of age, multiple sex partners and previous history of sexually transmitted diseases predispose women to cervical cancer. However, with the current global changes in population dynamics, a 4 -fold increase in cervical cancer related mortality is being predicted [18], necessitating immediate public health action to increase awareness and scale up preventive health service. Based on this, the study sought to investigate the knowledge and attitude of undergraduates towards cervical cancer in Imo State, Nigeria.

\section{Methodology}

The study was carried out at the Imo State University, Owerri, Nigeria. It is among the state-owned universities in Nigeria. It is located on latitude $5^{\circ} 30^{\prime} \mathrm{N}$ and $5^{\circ} 30.2^{\prime} \mathrm{N}$ longitude $7^{\circ} 2^{\prime} \mathrm{E}$ and $7^{\circ} 2.6^{\prime} \mathrm{E}$. The school offers both undergraduate and postgraduate programmes. The school is partitioned into two- "up" and "down" schools. The "up" school mainly houses the faculties of sciences-faculty of health science, faculty of science, faculty of environmental and faculty of agriculture and veterinary medicine and the "down" school containing seven faculties.

The "up" school was purposively selected for the study. This was because it has more number of female students than the "down" school. Out of the four faculties in the "up" school, the faculty of science was selected by the researcher using purposive sampling technique. This was based on the presence of higher number of female students in it. All the nine departments-Biochemistry, Botany, Zoology, Computer Science, Statistics, Chemistry, Mathematics, Microbiology and Physics-were selected using purposive sampling technique. This was done to promote representativeness. From each of the departments, 60 female students were selected using simple random sampling technique to give a total of 540 students, representing the total number of students in the University. However, the sample size was determined using Taro and Yamen's formula as shown below

$$
n=\frac{N}{1+N e^{2}}
$$

where

$n=$ sample size,

$N=$ population size,

$e=0.05^{2}$ (level of precision),

$n=\frac{540}{1+540(0.05)^{2}}$,

$n=229.78723404255$ approximating to the nearest whole number,

$n=230^{\circ}$.

Data for the study were obtained from pretested structured questionnaire. The questionnaire was designed according to the one used by Jarglaz et al. (2014) [19]. The instrument was validated using face and content validity. According to Akibile (2014) [20], face validity is the extent to which an instrument is per- 
ceived by experts or knowledgeable people in an area as covering the content area and measuring the concept whereas reliability is the extent to which an instrument gives consistent results. The instrument was validated by taking it to knowledgeable people in the subject area to assess whether it covered what it is meant to cover. A pilot study carried out to determine the reliability of the instrument using Chrowbach Alpha method showed that the instrument has a reliability coefficient $(r)$ of 0.81 . Data generated were analyzed using IBM-SPSS version 21. Percentage, mean score and Chi-Square were the statistical tools used in the analysis.

\section{Results}

\subsection{Demographic Characteristics of the Respondents}

Table 1 shows that the majority (81.7\%) of the respondents was aged between 21 - 30 years with a mean age of 25 years; the majority (88.7\%) was single, the majority (90.4\%) practiced Christianity and the majority (60.9\%) refused to disclose their family history of cervical cancer.

\subsection{Knowledge of Cervical Cancer}

Result in Figure 1 shows that the majority (70.0\%) of the respondents had low knowledge of cervical cancer. Result in Figure 2 also shows that a majority (53.0\%) of the respondents do not know the causes of cervical cancer.

Table 1. Socio-demographic characteristics.

\begin{tabular}{ccc}
\hline Socio-demographic characteristics & F & n $=230$ \\
Age & & \\
$<20$ & 14 & 6.1 \\
$21-30$ & 188 & 81.7 \\
$31-40$ & 21 & 9.1 \\
$41>$ & 7 & 3.0 \\
Marital Status & & 88.7 \\
Single & 204 & 11.3 \\
Married & 26 & \\
Religion & & 90.4 \\
Christianity & 208 & 7.8 \\
Islam & 18 & 1.7 \\
Other & 4 & 35.2 \\
Yes & & 60.9 \\
No & 91 & 3.9
\end{tabular}




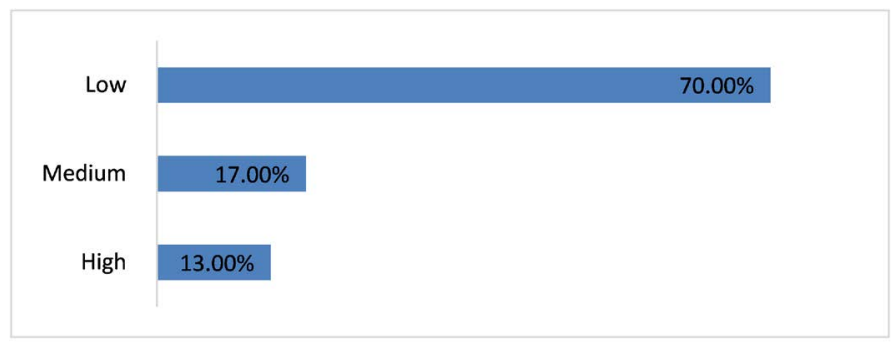

Figure 1. Knowledge level of cervical cancer.

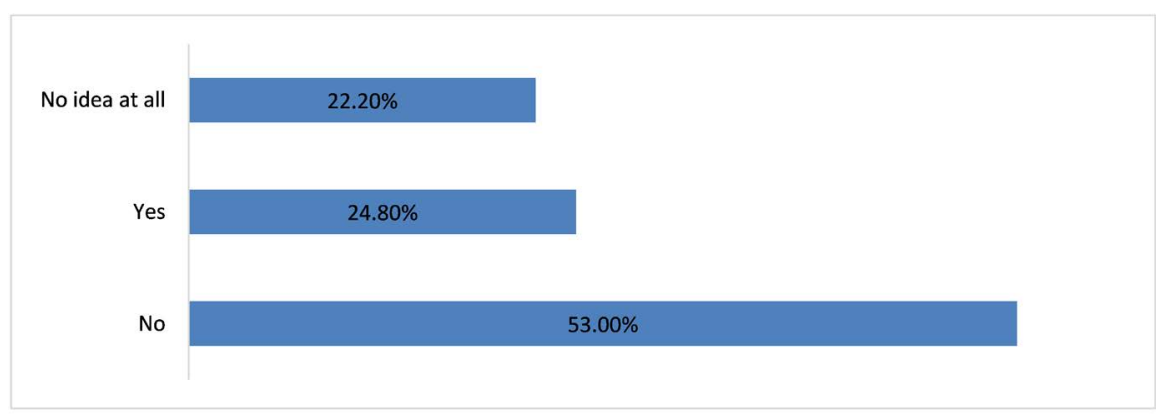

Figure 2. Knowledge of causes of cervical cancer.

\subsection{Attitude towards Cervical Cancer Screening}

Data in Table 2 reveals that a majority (82.6\%) of the respondents had never done pap smear test, a majority (60.4\%) were afraid of going for the test, a majority $(84.3 \%)$ were embarrassed if the test is done by a male medical doctor and a majority $(67.0 \%)$ thought that it is costly to do.

\subsection{Belief towards Cervical Cancer}

Table 3 shows that the majority (53.5\%) of the respondents disagreed that regular screening for cervical cancer is necessary once a woman attains the sexually active age, a greater proportion (40.9\%) did not agree that regular screening detects the infection at an early stage and a majority (70.6\%) did not agree that multiple sex partners increase the chances of contacting cervical cancer and the majority $(83.9 \%)$ did not agree that HPV is a deadly as HIV. However, only $36.1 \%$ had the correct belief that the use of condom can give protection against cervical cancer.

\subsection{Relationship between Level of Knowledge on Cervical Cancer and Attitude towards Screening for Cervical Cancer}

Table 4 shows that at $\mathrm{p}=0.000$ the respondents' level of knowledge about cervical cancer was significantly related to their attitude. Thus, the hypothesis which stated that students' level of knowledge about cervical cancer was not significantly related to their attitude was rejected.

\section{Discussion}

Knowledge and attitude of a society about a particular disease and factors 
Table 2. Attitude of respondents towards cervical cancer screening.

\begin{tabular}{ccc}
\hline Attitude statements & $\mathbf{F}$ & $\%$ \\
\hline Ever done pap smear test & $\mathbf{n}=\mathbf{2 3 0}$ & \\
Yes & 40 & 17.4 \\
No & 190 & 82.6 \\
Afraid of going for the test & 139 & 60.4 \\
Yes & 91 & 39.6 \\
No & & 84.3 \\
Embarrassed if it is done by a male doctor & 194 & 16.7 \\
Yes & 36 & \\
No & & 69.1 \\
I find pap smear irritating & 159 & 30.9 \\
Yes & 61 & \\
No & & 67.0 \\
It is costly & 154 & 33.0 \\
Yes & 76 & \\
No & &
\end{tabular}

Table 3. Belief towards cervical cancer.

\begin{tabular}{|c|c|c|}
\hline Belief statements & $\mathbf{F}$ & $\%$ \\
\hline \multicolumn{3}{|c|}{ Regular screening is necessary once sexually active } \\
\hline Don’t agree & 123 & 53.5 \\
\hline Agree & 63 & 27.4 \\
\hline Strongly agree & 44 & 19.1 \\
\hline \multicolumn{3}{|c|}{ Regular screening detects cancer early } \\
\hline Don't agree & 94 & 40.9 \\
\hline Agree & 62 & 27.0 \\
\hline Strongly agree & 74 & 32.2 \\
\hline \multicolumn{3}{|c|}{ Multiple sex partners increases chances of cervical cancer } \\
\hline Don't agree & 161 & 70.6 \\
\hline Agree & 52 & 22.2 \\
\hline Strongly agree & 17 & 32.0 \\
\hline \multicolumn{3}{|c|}{ Use of condom gives protection against cervical cancer } \\
\hline Don't agree & 82 & 35.6 \\
\hline Agree & 83 & 36.1 \\
\hline Strongly agree & 65 & 28.3 \\
\hline \multicolumn{3}{|c|}{$\mathrm{HPV}$ virus is as deadly as HIV virus } \\
\hline Don't agree & 193 & 83.9 \\
\hline Agree & 24 & 10.4 \\
\hline Strongly agree & 13 & 5.7 \\
\hline
\end{tabular}


Table 4. Pap smear test irritating (attitude 1) ${ }^{\star}$ Level of Knowledge.

\begin{tabular}{cccc}
\hline Chi-Square Tests & Value & df & Asymp. Sig. (2-sided) \\
\hline Pearson Chi-Square & $44.016^{\mathrm{a}}$ & 2 & 0.000 \\
Likelihood Ratio & 63.358 & 2 & 0.000 \\
Linear-by-Linear Association & 37.440 & 1 & 0.000 \\
\hline
\end{tabular}

$5 \%$ Significant level.

affecting their adherence to treatments is important as it helps in its control. From the result, it can be deduced that the respondents are young and within the sexually active and child bearing ages, indicating their vulnerability to cervical cancer. According to Cancer.Net (2019) [21] and World Health Organization (2014) [22], women between the late teens and mid 30s have a high risk of contracting the infection. Though the majority of the respondents are single but their age requires them to have a knowledge of the infection. Furthermore, the religion of most of the women studied has a relatively high tolerance for information dissemination and thus might positively influence their knowledge and attitude towards the infection. However, the refusal of a majority (60.9\%) of the respondents to disclose their family history about cervical cancer could be attributed to cultural factors that forbid women from discussing issues pertaining certain parts of their bodies with strangers. Mulder et al. (1992) [23] noted that women especially those in rural communities display distrust for those they do not know on a personal level when their health is involved.

Further, the result found that the knowledge of cervical cancer among the respondents was low. This could probably be due to the low exposure of the respondents to information about the disease by health professionals. Low knowledge of an infectious disease could promote its vulnerability and subsequently outbreak while high knowledge could stimulate behaviours that would potentially lead to a reduction in its outbreak. According to Funk et al. (2009) [24], a change in behavior can be prompted without witnessing the disease itself but by being informed about it by others. They argued further that spreading information about a disease will reduce its incidence and outbreak. Ogbonna (2017) [14] found that the knowledge of cervical cancer among students of sub-Saharan African origin was low. Supporting this, Ahmed et al. (2013) [25] reported that the knowledge of risk factors for cervical cancer was generally poor in Nigeria. This could be attributed to poor sensitization on the disease by health workers and other relevant agencies.

The result suggests a generally negative attitude towards cervical cancer screening among the respondents. This however might predispose the respondents to the disease thus encouraging its spread as lack of screening will prevent the detection of the disease at early stages. The negative attitude is not unconnected to the low knowledge level of the infection as screening is a necessary measure to control its spread. Ogbonna (2017) [14] reported poor perception of the disease in sub-Saharan Africa. Adefuye (2006) [26] opined that better facili- 
ties, provision of more female staff and offering service at cheaper costs at the screening centres will promote participation in screening [25]. Aboyeji (2004)

[27] argued that ignorance, misconception and religious beliefs also influence attitude towards cervical cancer screening.

The result further suggests wrong beliefs about the infection which could have resulted from ignorance. The negative belief about the infection might be as a result of the respondents' social, economic and cultural backgrounds. Negative belief about an infection may prevent the deployment of necessary precautions and treatments against it thus encouraging the spread. Baghianimoghaddam et al. (2010) [28] found a relationship between belief and the identification of preventive behaviours. Diekema (2014) [29] reported a considerable resistance to vaccination among school children by their parents in the US due to the parents' unfavourbale belief towards vaccination.

The hypothesis tested revealed that the respondents' knowledge level about cervical cancer influenced their attitude. Eagly and Chaiken (1993) [30] established a relationship between knowledge and attitude toward and attitude. Heisler et al. [31] opined that knowledge of a disease could lead to the adoption of positive towards the disease. According to Steed et al. (2003) [32], increased knowledge about a disease is associated with positive attitudes which enhance disease-associated reduction, greater treatment receptiveness and a more positive perception of health and social acceptance.

\section{Conclusion}

The knowledge of cervical cancer among undergraduates in the study area was generally very low in spite of their high educational attainment. Also, they lacked knowledge of the causes of the infection. The attitude towards cervical cancer screening was also negative. This suggests that the students are yet to acquire sound knowledge about the disease which will encourage actions against its prevention and treatment. However, a significant relationship was found to exist between knowledge and attitude towards cervical cancer among the students. Increasing the knowledge of the students on the disease is expected to improve their attitude towards screening. Based on the findings of the study, radical sensitization campaigns should be mounted targeting mainly women in vulnerable age ranges. Also, awareness programmes can be organized in universities to help raise the knowledge of the disease among students.

\section{Limitation of the Study}

This study is limited by its small geographic area and moderate sample size.

\section{Conflicts of Interest}

The authors declare no conflicts of interest regarding the publication of this paper. 


\section{References}

[1] Neerja, B., Aoki, D., Sharma, D.N. and Sankaranarayanan, R. (2018) Cancer of the Cervix Uteri. International Journal of Gynecology and Obstetrics, 143, 22-36. https://doi.org/10.1002/ijgo.12611

[2] Jedy, E.E., Dareng, E.O., Adebamawo, S.N., Odutola, M. and Igbinoba, F. (2016) The Burden of HPV Associated Cancers in Two Regions in Nigeria 2012-2014. Cancer Epidemiology, 45, 91-97. https://doi.org/10.1016/j.canep.2016.10.008

[3] Bosch, F.X., Lorincz, A., Munoz, N., Meijer, C.J. and Shah, K.V. (2002) The Causal Relation between Human Papillomavirus and Cervical Cancer. Journal of Clinical Pathology, 55, 244-265.

[4] International Agency for Research on Cancer, IARC (2007) IARC Monographs on the Evaluation of Carcinogenic Risks to Humans Volume 90. IARC Working Group on the Evaluation of Carcinogenic Risks to Humans, Lyon, 15-22 February 2007.

[5] Arbyn, M., Weiderpass, E., Bruni, L., de Sanjose, S., Saraiya, M. and Ferlay, J. (2019) Estimates of Incidence and Mortality of Cervical Cancer in 2018: A Worldwide Analysis. The Lancet, 8, E191-E203. https://doi.org/10.1016/S2214-109X(19)30482-6

[6] American Cancer Society (2013) Cancer Facts and Figures. American Cancer Society, Atlanta.

[7] Nwankwo, K.C., Aniebue, U.U., Agunwa, Anarado, A.N. and Agunwa, E. (2011) Knowledge Attitudes and Practices of Cervical Cancer Screening among Urban and Rural Nigerian Women: A Call for Education and Mass Screening. European Journal of Cancer Care, 20, 367-375. https://doi.org/10.1111/j.1365-2354.2009.01175.x

[8] Bruni, L., Albero, G., Serrano, B., Mena, M., Gomez, D., Munoz, J., Bosch, F.X. and de Sanjose, S. (2019) ICO/IARC Information Centre on HPV and Cancer (HPV Information Centre). Human Papillomavirus and Related Diseases in Africa. Summary Report 17 June.

[9] World Health Organization (2015) Projection of Mortality and Causes of Death, 2015 and 2030.

https://www.who.int/healthinfo/global_burden_disease/projections/en/

[10] Ferlay, J., Soerjomantaram, I., Ervik, M., Dikshit, R., Eser, S. and Mathers, C. (2012) Cancer Incidence and Mortality Worldwide: IARC CancerBase No. 11. International Agency for Research on Cancer, Lyon.

[11] Beddoe, A.M. (2019) Elimination of Cervical Cancer: Challenges for Developing Countries. eCancer, 13, 975. https://doi.org/10.3332/ecancer.2019.975

[12] Bisi-Onyemaechi, A.I., Chikani, U.N and Nduagubam, O. (2006) Reducing Incidence of Cervical Cancer: Knowledge and Attitudes of Caregivers in Nigerian City to Human Papilloma Virus Vaccination. Infectious Agents and Cancer, 13, Article No.: 29. https://doi.org/10.1186/s13027-018-0202-9

[13] Walker, A.R., Micheolow, P.M. and Walker, B.F. (2002) Cervix Cancer in African Women in Durban, South Africa. International Journal of Gynecology and Obstetrics, 79, 55-46. https://doi.org/10.1016/S0020-7292(02)00178-9

[14] Ogbonna, F.S. (2017) Knowledge, Attitude and Experience of Cervical Cancer and Screening among Sub-Saharan African Female Students in UK Universities. Annals of African Medicines, 16, 18-23.

[15] Ayinde, O.A. and Omigbodun, A.O. (2003) Knowledge, Attitude and Practices Related to Prevention of Cancer of the Cervix among Female Health Workers in Iba- 
dan. Journal of Obstetrics and Gynecology, 23, 59-62. https://doi.org/10.1080/0144361021000043272

[16] Buga, G.A. (1998) Cervical Cancer Awareness and Risk Factors among Female University Students. East African Medical Journal, 75, 411-416.

[17] Anorlu, R.I., Banjo, A.A. and Odoemhun, C. (2000) Cervical Cancer and Cervical Cancer Screening: Level of Awareness in Women Attending a Primary Healthcare Facility in Lagos. Nigerian Postgraduate Medical Journal, 70, 25-28.

[18] Kerr, D.J. and Fiander, A.N. (2009) Towards Prevention of Cervical Cancer in Africa. Report from Meeting at St' Catherine's College, Oxford.

[19] Jarglaz, K., Tomaszeweski, K.A., Kamzol, W., Pusulluoglu, M. and Krzemieniecki, K. (2014) Creating and Field-Testing the Questionnaire for the Assessment of Knowledge about Cervical Cancer among Schoolgirls and Female Students. Journal of Gynecology and Oncology, 25, 81-89. https://doi.org/10.3802/jgo.2014.25.2.81

[20] Akibile, L.A. (2004) Measurement in Agricultural Extension. In: Olowu, T.A., Ed., Research Methods in Agricultural Extension. Agricultural Extension Society of Nigeria (AESON), Agricultural and Rural Training Management Training Institute (ARMTI), Illorin, Nigeria.

[21] Cancer.Net (2019) Cervical Cancer: Risk Factors. http://www.cancer.net/cancer-types/cervical-cancer/rik-factors

[22] World Health Organization, WHO (2014) The Health of the People: What Works? The African Regional Health Report 2014. WHO Regional Office for Africa, Congo.

[23] Mulder, P.L., Kenkel, M.B., Shellenberger, S., Constantine, M.G., Streiegel, R., Sears, S.F., Jumper-Thurman, P., Kalodner, M., Danda, C.E. and Hager, A. (1992) The Behavioural Healthcare Needs of Rural Women.

[24] Funk, S., Gilad, E., Watkins, C. and Jansen, V.A.A. (2013) The Spread of Awareness and Its Impact on Epidemic Outbreaks. Proceedings of the National Academy of Science, 106, 6872-6877. https://doi.org/10.1073/pnas.0810762106

[25] Ahmed, S.A., Sabitu, K., Idris, S.H and Ahmed, R. (2013) Knowledge, attitude and practice of cervical cancer screening among market women in Zaria, Nigeria. Nigerian Medical Journal, 54, 316-319. https://doi.org/10.4103/0300-1652.122337

[26] Adefuye, P.O. (2006) Knowledge and Practice of Cervical Cancer Screening (Pap Smear) among Female Nurses in Nnewi, South Eastern Nigeria. Nigeria Medical Practice, 50, 19-22. https://doi.org/10.4314/nmp.v50i1.28829

[27] Aboyeji, P.A., Ijaiya, M.A. and Jimoh, A.A. (2004) Knowledge, Attitude and Practice of Cervical Smear as a Screening Procedure for Cervical Cancer in Ilorin, Nigeria. Tropical Journal of Obstetrics Gynecology, 21, 114-117. https://doi.org/10.4314/tjog.v21i2.14482

[28] Baghianimoghaddam, M.H., Forghani, H., Zoldhadi, R., Rahaii, Z. and Khani, P. (2010) Health Belief Model and HIV/AIDS among High School Female Students in Yazd, Iran. Journal of Research in medical Sciences, 15, 189-190.

[29] Diekema, D.S. (2014) Personal Belief Exemptions from School Vaccination Requirements. Annual Review of Public Health, 35, 275-292. https://doi.org/10.1146/annurev-publhealth-032013-182452

[30] Eagly, A.H. and Chaiken, S. (1993) The Psychology of Attitudes. Wadsworth Group, Belmont.

[31] Heisler, M., Langa, K.M., Eby, E.L., Kabeto, L.U. and Piette, J.D. (2004) The Health Effects of Restricting Prescription Medication Use Because of Cost. Medical Care, 42, 626-634. https://doi.org/10.1097/01.mlr.0000129352.36733.cc 
[32] Steed, L., Cooke, D. and Newman, S. (2003) A Systematic Review of Psychological Outcomes Following Education, Self-Management and Psychological Interventions in Diabetes Mellitus. Patient Education and Counselling, 51, 5-15.

https://doi.org/10.1016/S0738-3991(02)00213-6. 